\title{
Evaluation Indicator of Regional Energy Vulnerability to Climate Change - Spatial and Temporal Analysis
}

Luis RAMOS ( $D$ luisramosramire20@gmail.com )

NIPEA

Fredy GUEVARA

Universidad Nacional de Colombia

Marco GUEVARA

University of Strasbourg: Universite de Strasbourg

\section{Research Article}

Keywords: energy planning, global warming, renewable energy sources, energy transition, energy matrix

Posted Date: March 10th, 2021

DOl: https://doi.org/10.21203/rs.3.rs-235570/v1

License: (1) This work is licensed under a Creative Commons Attribution 4.0 International License.

Read Full License 


\title{
Evaluation indicator of regional energy vulnerability to climate change - spatial and temporal analysis
}

\author{
Luis, RAMOS ${ }^{\text {a*}}$; Fredy, GUEVARA ${ }^{\text {cd. }}$, Marco, GUEVARA bde \\ a Núcleo Internacional de Pensamiento en Epistemología Ambiental (NIPEA), \\ Universidad Nacional Abierta y a Distancia, Bogotá 111071, \\ Colombia. \\ ${ }^{\mathrm{b}}$ Conservación, Bioprospección y Desarrollo Sostenible (COBIDES), \\ Universidad Nacional Abierta y a Distancia. Escuela de Ciencias Agrarias, Pecuarias y del Medio Ambiente \\ (ECAPMA) Bogotá 111071, \\ Colombia. \\ ${ }^{\mathrm{c}}$ Grupo de Investigación de Calidad del Aire (GICA), Universidad Nacional de Colombia. Departamento de \\ Ingeniería Química y Ambiental. Bogotá 111071, Colombia. \\ ${ }^{\mathrm{d}}$ Smart and Simple Engineering S.A.S (S\&S S.A.S). Scientific Research Department. Bogotá 111071, \\ Colombia. \\ ${ }^{\mathrm{e}}$ Laboratoire Image Ville Environnement (LIVE), Université de Strasbourg. Strasbourg 67000, France.
}

*Corresponding author: luisramosramire20@gmail.com

\section{ORCID:}

Luis Angel RAMOS: 0000-0002-9087-112X

Marco Andrés GUEVARA-LUNA: 0000-0002-1541-4332

Fredy Alejandro GUEVARA-LUNA: 0000-0003-2742-8982

\begin{abstract}
Climate change might affect energy production and therefore the energy security of a country or region. This vulnerability situation may affect Renewable Energy Sources (RES) such as hydroelectric and has consequences on effective energy transition. Since the transition to RES is a key for decarbonizing the economy in line with the Paris Agreement this situation is critical for many countries in which their energy systems are linked to resources strongly affected by climate. The aim of this study is to purpose a vulnerability indicator (VI) to evaluate the electric energy vulnerability of an on-grid system to climate change at national and regional level taking as base the case of study of Colombia, a country with a system based on 70\% RES. VI is computed with different variables that may be related to climate change, the energy matrix, and vulnerability. Principal Component Analysis (PCA) was used to select the variables involved in the VI calculation. The VI was calculated for the whole country and the 32 departments (states) showing that the regions with the larger vulnerability correspond to the more energy demanding regions. These vulnerable regions to climate change are more than $50 \%$ of the maximum possible vulnerability, meanwhile, the vulnerability of the whole country was estimated as $43 \%$. The analysis was developed for the current situation of Colombia in which there are two regions: interconnected (SIN) and not-interconnected (ZNI) areas.
\end{abstract}

\section{Keywords}

energy planning; global warming; renewable energy sources; energy transition; energy matrix 


\section{Highlights}

- A new vulnerability indicator (VI) to estimate the energy vulnerability of a country or region to climate change is proposed and used for the case of the study of Colombia.

- A link between climate change and the increasing energy vulnerability in Colombia was evidenced based on the analysis performed.

- VI was used for the case of Colombia showing that the vulnerability of the country is $43 \%$ of the maximum possible, and the most vulnerable regions have more than $50 \%$ of the maximum vulnerability.

- 7 variables related to climate change, the energy matrix, and climate change were selected for the VI calculation using the PCA and correlation matrix approaches.

\section{Introduction}

Energy transition has turned imminent. Since the human appearance on the globe, the temperature has been stable until the 19th century with the beginning of the industrial revolution (Houghton and Woodwell 1989; Wallace and Hobbs 2006). Between 1850 and 2012, the near-surface air temperature increased by $0.8{ }^{\circ} \mathrm{C}$ mainly due to anthropogenic emissions produced during the energy production demanded by transport, industry, residential, among other sectors (González 2007; Jacobson 2020; Seba 2014; Seba and James 2017). This trend is dangerous for many countries in which their energy resources are linked with resources strongly affected by climate change. The transition to Renewable Energy Sources (RES) is key for decarbonizing the economy in line with the Paris Agreement, to reduce greenhouse gas (GHG) emissions by $80-95 \%$ by 2050 from a 1990 baseline (Fernández-Reyes 2016).

Colombia is a developing country with a population of more than 50 million inhabitants in 2020. It is an Andean country that produces around $75.5 \mathrm{TWh} / \mathrm{yr}$ of electric energy(UPME 2020). Colombia is currently energetically autonomous and has an energy mix that produces around $70 \%$ of its electric energy based on renewables, mostly hydropower production facilities, only a few small RES-based solar and wind projects take place currently in the country, and they do not represent more than $2 \%$ in the near future (UPME 2020). The current energy situation makes the country sensitive to climate change. Large scale blackouts have been registered in Colombia in 1992, and more recently in 2016 during the most recent El Niño-Southern Oscillation (ENSO) period due to the decrease in the dam and reservoir levels (Mateus 2016). The aforementioned situation is evidence that during strong dry seasons, mainly characterized by the ENSO, the country faces a lack of energy supply leading to blackouts (Cuadros et al. 2019). Additionally, the electric energy demand is trending to increase due to the development processes, the energy transition, migration from the countryside to urban areas, and important population growth due to the massive immigration of refugees from Venezuela in recent years(Berg et al. 2020; Betts 2019). These two issues: the hydropower based energy matrix and the increasing electric energy demand, will drive the decision-making process regarding the energy strategies of the country in the next years.

To assess the vulnerability of regions and countries to climate change several studies have been published. The RES vulnerability has been assessed in 2012 considering several factors such as endowment, infrastructure, distribution, and transmission of energy based on many studies (Schaeffer et al. 2012). Energy is identified as one of the areas with more impact on climate change (Mideksa and Kallbekken 2010), authors also mentioned that energy supply is impacted as a result of climate alteration since variables such as wind speed, river flow, evaporation rates, and solar radiation are changing. Additionally, it has been found that climate change is 
affecting the performance of non-RES (mainly thermal and nuclear power plants) in Russia (Klimenko et al. 2018).

The main aim of this study is to propose a vulnerability indicator (VI) to evaluate the electric energy vulnerability of an on-grid system to climate change at national and regional level taking as base the case of study of Colombia. The proposed indicator is based on the different variables that may be related to climate change, the energy matrix, and therefore the vulnerability. To identify the variables that must be used for the indicator calculation the Principal Component Analysis (PCA) method was used since this approach allows identifying the relationships between the different variables. The data used was retrieved for the last 20 years at the country level and the last 7 years at the regional level.

The VI was calculated for the whole country and the 32 departments (states). The spatial comparison between the different geographical locations was evaluated using different regional distributions of the VI. The method based on the indicator proposed is designed to be easily adapted and used in other countries or regions 101 worldwide.

\section{Methodology}

103

104

105

106

107

108

109

110

\subsection{Current Situation of energy in Colombia}

The current situation of Colombia is described in terms of the climate and energy variables. Climate and energy data were retrieved for the last 20 years nationwide and last seven years to the departmental level. Climate data was downloaded from the ERA-5 database from ECMWF (European Centre for Medium-Range Weather Forecasts)(ECMWF 2020).

The energy demand and production were obtained from the historic records from UPME (Unidad de Planeación Minero Energética). Figure 1a shows the electric energy demand (ED) per department. Figure 1b shows the areas of the country connected to the grid (SIN) and off-grid regions (ZNI), the percentages in Figure 1b are linked with the total area from Colombia. 11'389407 of SIN users were reported in 2018, differently a smaller number of users were reported for ZNI: 207653 (XM S.A. E.S.P. 2021a). The relationship between population (Pop) and ED from 2000 to 2019 is shown in Figure 2. Population data were obtained from the World Data Bank (The World Bank 2021). 


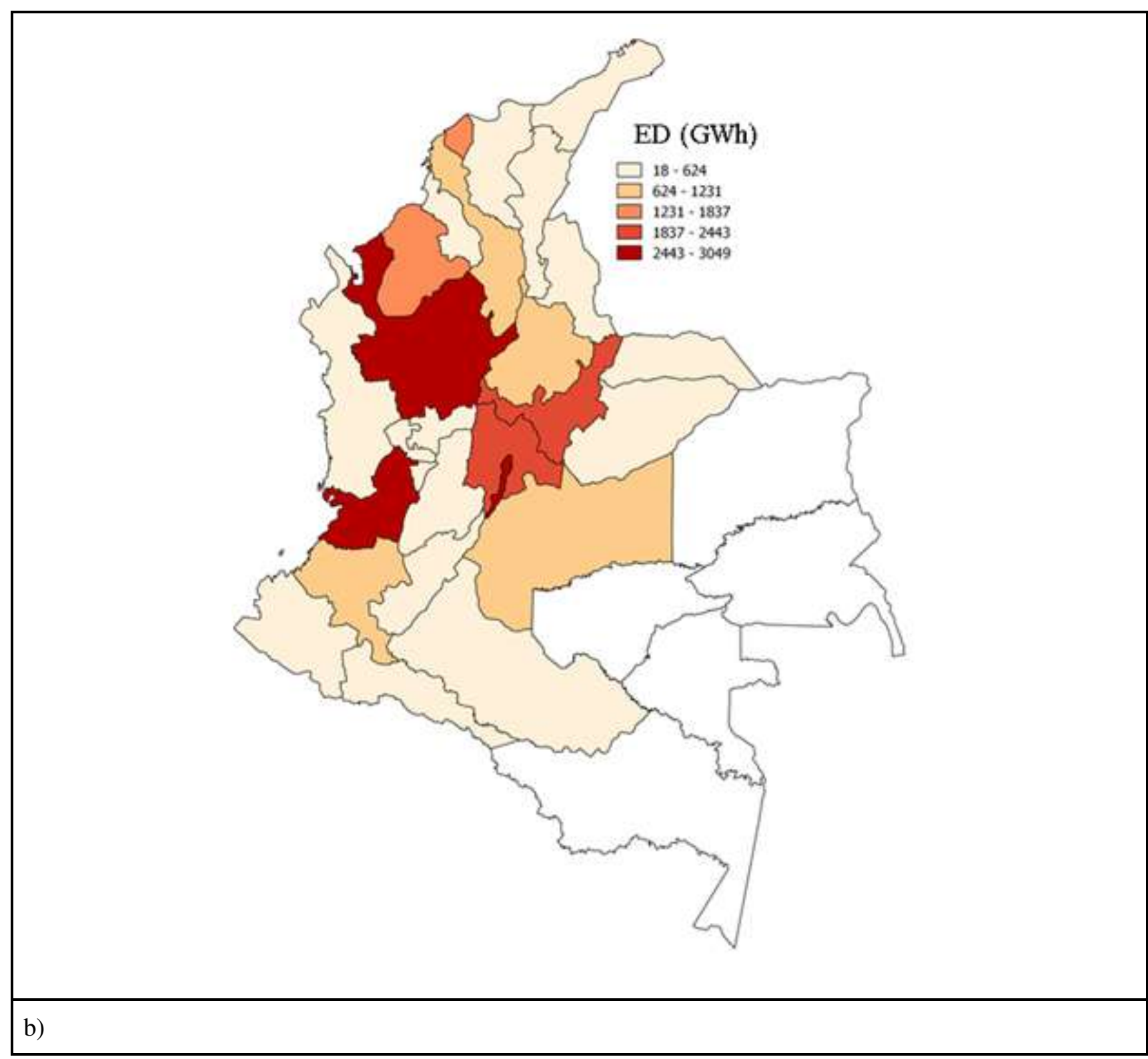




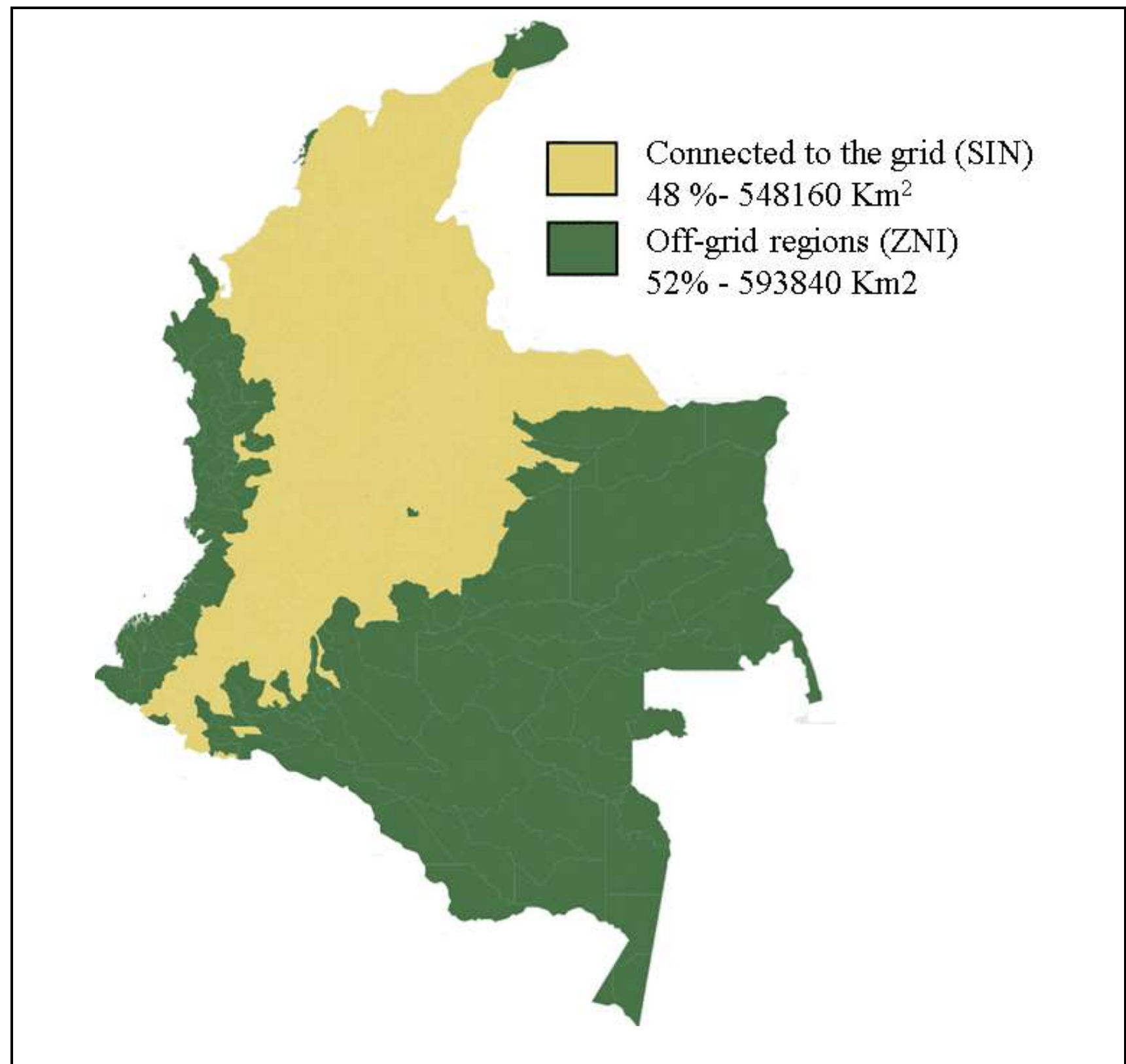

118 Figure 1. The current electric energy situation in Colombia: a) Spatial distribution of electric energy 119 demand (ED) in 2019, b) Supply system coverage in terms of areas connected to the grid (SIN) and off120 grid regions (ZNI). (Adapted from:(López et al. 2020)) 


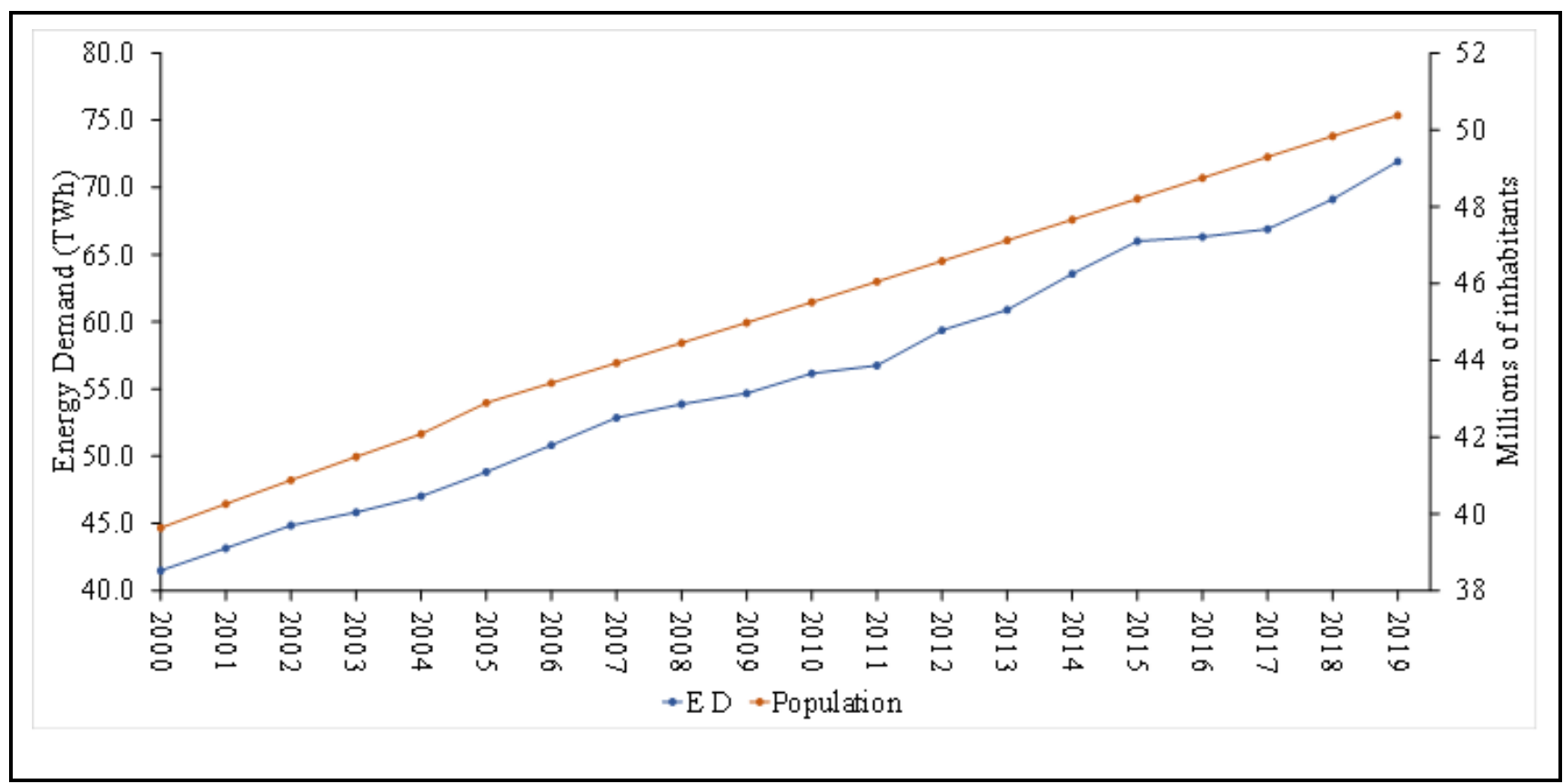

Figure 2. Population and Energy Demand (ED) in Colombia from 2000 to 2019.

125

126

127

128

129

130

131

132

133

134

135

136

137

138

139

140

141

142

143

144

145

146

Figure 3a shows the electric energy production (EP) and the ED of Colombia between 2000 and 2020. Differences between demand and production are also shown to identify the strong deficit of energy production since 2015. Between the years 2003 and 2015, no deficit of energy supply was presented, even so in the early 2000s small deficits took place in the country. Additionally, Figure $3 \mathrm{a}$ also shows the increasing trend of ED and energy production with time. The data used for Figure 3a were retrieved from the UPME website (UPME 2021). This data is composed of ED and production records per month for the whole country.

Figure $3 \mathrm{~b}$ shows the composition of the energy mix based on the energy generation sources per month between 19 august 2019 and 20 August 2020, data was retrieved from SIEL (UPME 2020), the current electric energy mix is characterized by hydropower as the main production source with $70.4 \%$, followed by natural gas and coal with a $13.7 \%$ and $12.7 \%$ respectively. 


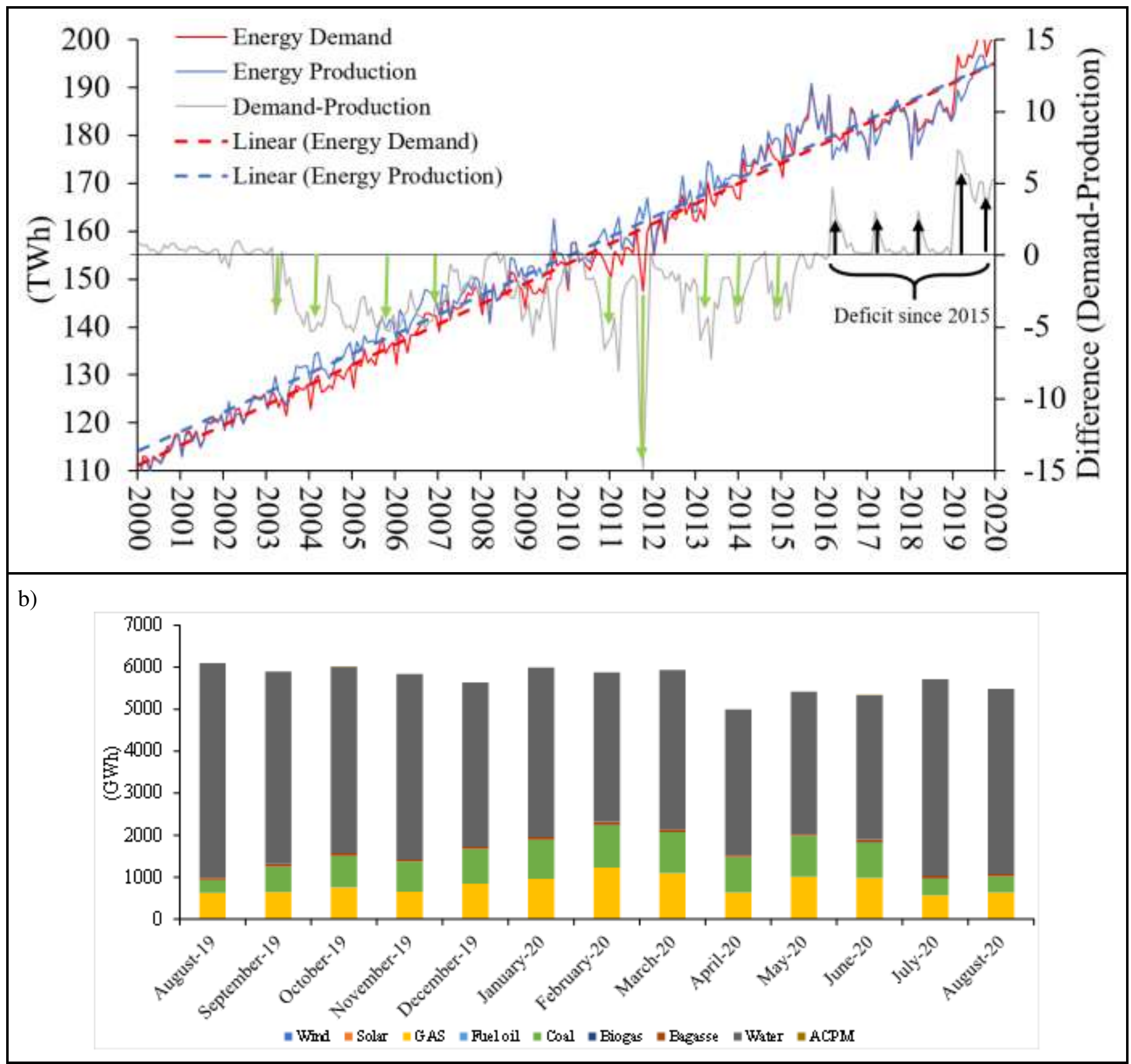

Figure 3. Total energy production and energy demand of Colombia: a) Total electric energy production (EP) and electric energy demand (ED) trend from 2000 to 2020, and b) Energy production by the source from august 2019 to august 2020 (UPME 2020).

\subsection{Vulnerability indicator (VI)}

The indicator utilizes several variables for which the time profiles must be retrieved as the first step in the calculation of the indicator. The variables must correspond to the same spatial area of study, i.e. the same region, city, or country, and during the same period of time. Profiles of each used variable should be based on the same time basis i.e. daily, weekly, monthly or yearly data. These variables might be related to climate change and between them in order to be significant for the indicator calculation of the region of study. Variables can be linked with different types of fields such as economic, climatic, and electric. Since the index calculation is focussed on the variables strongly linked to climate change, to identify these variables a statistical method such 
as PCA (Principal Component Analysis) (Abdi and Williams 2010) can be used. In addition, for some clusters with many variables, it is necessary to use a correlation matrix to choose the most representative variable of the cluster (Bartholomew 2010).

The Vulnerability Indicator of the region $r\left(V I_{r}\right)$ can be computed using the equation (1). In this equation, $W_{k}$ is the weighting factor of the variable $k$, and $S_{k}$ is the score factor of the time with increasing vulnerability for variable $k$.

$$
V I_{r}=\sum_{k} \quad W_{k} * S_{k}
$$

The scoring factor is calculated according to equation (2), in which $n$ is the time unit (e.g. months, years, etc.), and $t_{n}$ can take the value of 0 or 1 in each timestep depending if the vulnerability in terms of the variable $k$ decreases or increases respectively.

$$
\begin{aligned}
& \qquad S_{k}=\sum_{n} t_{n} \text { (2) } \\
& t_{n=0} \text { if the vulnerability does not increase during time } n \\
& t_{n}=1 \text { if the vulnerability increases during time } n
\end{aligned}
$$

The weighting factor is calculated according to equation (3), when $\sigma$ is the standard deviation of variables identified as the suitable ones for the vulnerability consideration, in this expression the indexes $i$ and $k$ denote the aforementioned variables. Additionally, the condition of equation (4) must be complied with in any case.

$$
\begin{gathered}
W_{k}=\frac{\sigma_{k}}{\sum_{i} \sigma_{i}} \\
\sum_{k} W_{k}=1
\end{gathered}
$$

With a good indicator, it might be possible to compare against cases (regions, cities, or countries), and against the minimum and maximum possible values. The formulation of $V I{ }_{r}$ presented in this study allows this type of analysis. To perform this analysis the calculation of the maximum possible $V I{ }_{r}$ can be carried out taking the maximum possible $S_{k}$ value as $S_{k}=n$. This will lead to equation (5). Differently, the minimum possible $V I{ }_{r}$ will always take the value of zero, see equation (6).

$$
\begin{gathered}
\text { maximum } V I_{r}=S_{k}=n \\
\text { minimum } V I_{r}=0
\end{gathered}
$$

With the results from equations (1), (5), and (6) it is possible to estimate the vulnerability of region $\mathrm{r}$ as the vulnerability percentage $(V \%)$, see equation (7). This percentage can be used as a complementary indicator of the sensitivity of $\mathrm{r}$ to climate change based on the variables used, and the period of time evaluated. A high $V \%$ for the region, city or country will mean $r$ has been strongly affected by climate change, and a low $V \%$ will mean 


r has not

not been

strongly

affected

by

climate

change.

$$
V \%=\frac{V I_{r}}{\text { maximum } V I_{r}} * 100
$$

\section{Discussion with already published works on similar topics from other parts of the world}

Climate change vulnerability has been considered in different ways in already published studies world wide. Methodologies change according to the study area, e.g. some have been developed in border regions (Scholze et al. 2020), or islands (Genave et al. 2020). Other studies have proposed a vulnerability index calculation methodology for its global application(Gatto 2019).

Scholze (2020) shows an assessment of climate change in the Trinational Upper Rhine Region more, the border region between France, Germany and Switzerland. This research uses a specific set of variables with high spatial resolution to define the vulnerability linked to a spatial approach. Variables were selected based on different vulnerability concepts, taking account indicators such as climatic stress, exposure, sensitivity and impact. Indicator data was retrieved from satellite based databases. Genave (2020) reports the assessment of energy vulnerability in small islands, the variables used were selected taking into account guidelines from literature (International Atomic Energy Agency, 2005), the data used was retrieved from the World Data Bank, data used is related to economic, social and environmental fields. The Gatto (2019) methodology uses less variables than the other studies already published, the dataset was built with records between 1960 and 2016 a relatively long time range.

The variables selection in the vulnerability index of energy to climate change strongly depends on the study area. For some cases the difference between energy and environmental policies makes necessary the use of more specific data. In any case can be seen the use of satellite-based data is possible and a good source of information for the vulnerability the analyses such as the presented in this article.

Some already published studies used the PCA method to select variables to be used in the calculation of vulnerability to climate change (Gatto 2019; Genave et al. 2020). Once with the variables selected the authors bring a weighting for each variable in order to consider its impact. In this step Scholze (2020) uses an algorithm to classify raster files and obtain the vulnerability index. Differently, Genave (2020) uses The Benefit-of-theDoubt (BoD) Model for the weighting.

In this research data used was retrieved from different sources of information e.g. local agencies reports, public databases and satellite-based data. We apply the PCA approach to select the variables used in the calculation of the VI, the weighting of variables was performed based on the standard deviation of the independent variabletime-series. This study is performed at country scale.

\section{Results and discussion}

\subsection{Variables selection}

The raw input variables used in this research were Temperature in ${ }^{\circ} \mathrm{C}(\mathrm{T})$, Precipitation in $\mathrm{mm}(\mathrm{P})$, Population (Pop) in terms of millions of inhabitants, Gross domestic product (Total GDP) in US-dollars, $\mathrm{CO}_{2}$ equivalent emissions in Ton of $\mathrm{CO}_{2 \text {-eq }}$ per year $(\mathrm{CE})$, Water reserves volume from dams $(\mathrm{RV})$ in million of $\mathrm{m}^{3}$, Energy 
reserves based on RV (ER), Energy demand (ED), Energy production (EP), Energy imports (EI) and Energy exports (EE). Energy quantities ER, ED, EP, EI, and EE are in GWh. These variables have different trends in time, and the relationships between them must be considered to evaluate properly the vulnerability of the system to climate change. Relationships between these variables were analyzed using the PCA method (Figure 4a).

Figure 4a. shows the PCA results for the aforementioned variables, the test performed has representativeness of the 2 main components of $59.9 \%$ and $14.8 \%$ for Dim 1 and Dim 2 respectively. The studied variables are well represented by the 2 main components (Dim 1 and Dim 2) in the performed PCA test since the representativeness of Dim 1 + Dim 2 exceeds 70\% (Figure 4a) (Abdi and Williams 2010).

As a result of the PCA (Figure 4a) analysis, 4 clusters were identified: cluster 1 composed by RV and EI; cluster 2 composed by ER; cluster 3 composed by P and EE; and cluster 4 composed by CE, Pop, ED, T, GDP, and EP. These clusters are composed of variables with similar temporal trends, i.e. variables within the same cluster decrease or increase with time (Abdi and Williams 2010).

For clusters 1,2, and 3 one single variable was selected as the representative of the set of variables within each cluster. The criterion used was the strength of the correlation in terms of the arrow length, i.e. the variable with the larger arrow (the arrow closer to the circle) was selected. The cluster 4 has several variables, and the criterion used for the cluster 1,2, and 3 is not applicable, for this reason, to select the representative variable of cluster 4, a correlation matrix analysis was performed for the variables within the cluster 4 (Figure 4b). For cluster 4 the ED was selected as the representative variable since according to the correlation matrix it has a higher correlation coefficient than the other variables within the same cluster.

According to the analysis performed the selected variables for the vulnerability index calculation were ER, EE, EI, and ED since they are representative of the identified clusters 1,2,3, and 4 respectively.

a) 


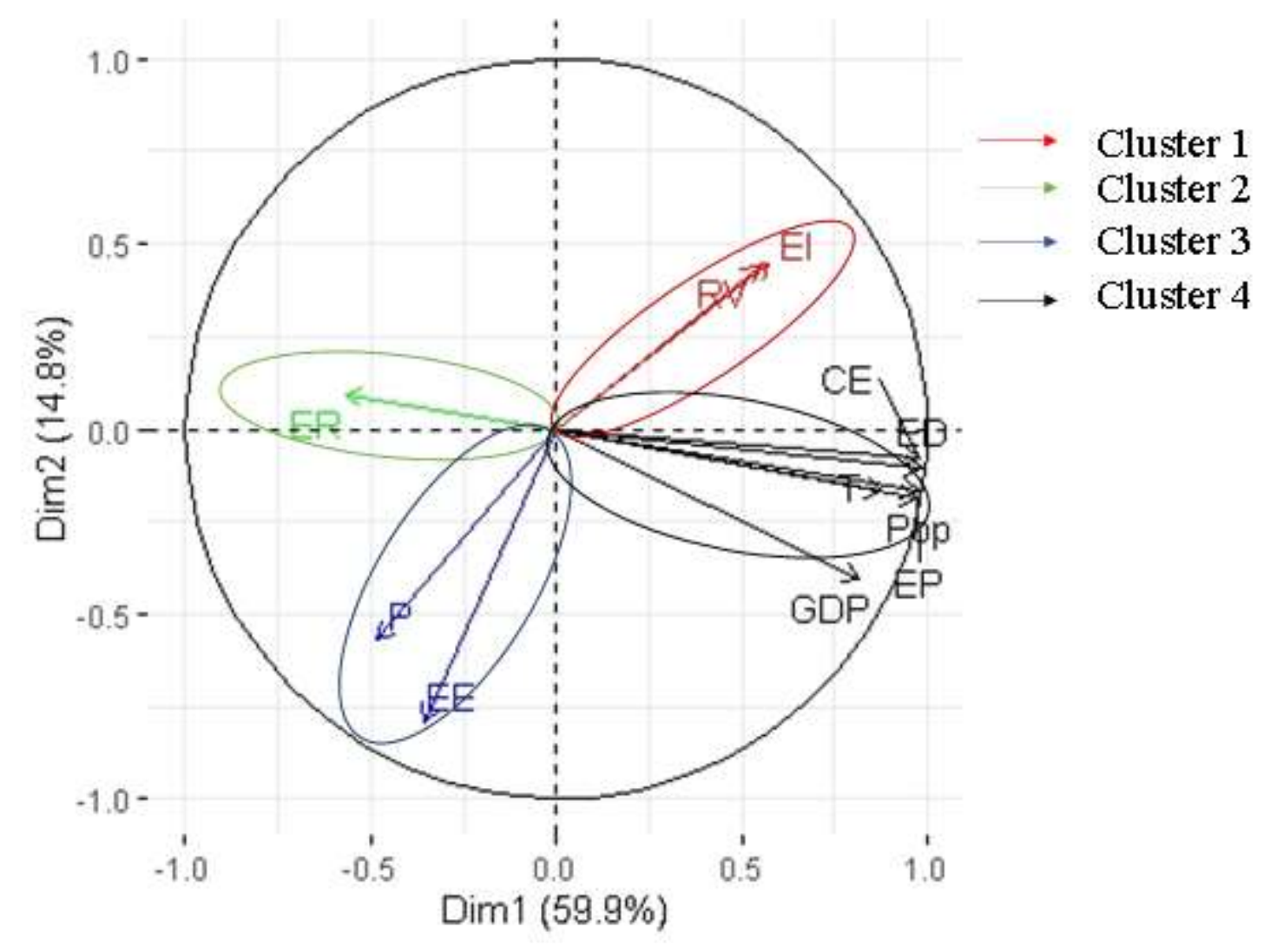

b)

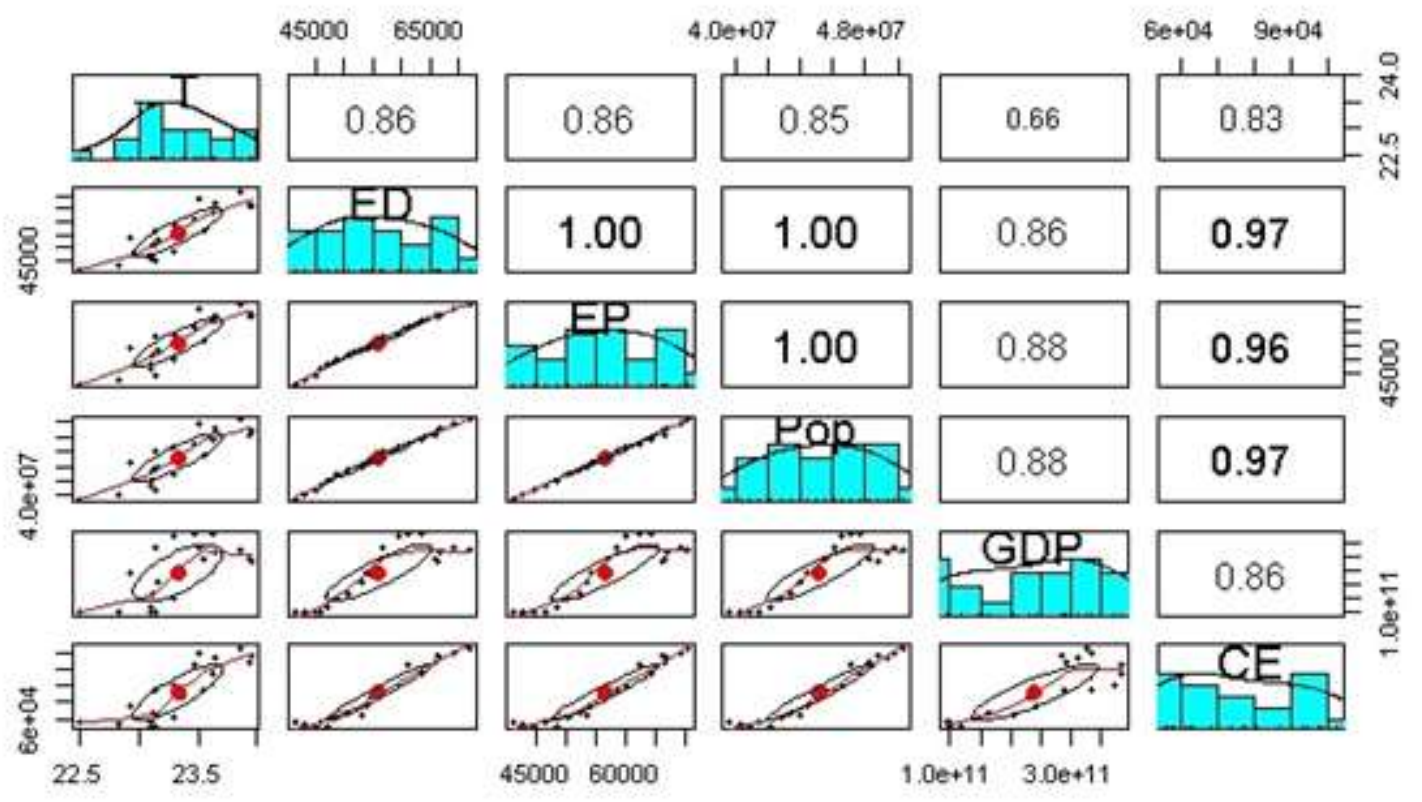

Figure 4. Selection of variables for calculation of the vulnerability index: (a) PCA (Principal Component Analysis) to identify the representative variables for vulnerability index calculation, (b) Correlation Matrix analysis for Cluster 4.

278 Variables within the same cluster have a direct relationship, this can be verified for cluster 1, variables in cluster 2791 increase with time, e.i. EI increases during the period of time studied (Figure 5b) just as RV does. Based on 
the vectors plot in Figure 4a. EI and RV are inversely proportional to the EE (clusters 1 and 3), e.i. EI increases with RV, but at the same time, EE decreases with time. The increase of EI and RV is explained by the installation of new dams between January 2000 and January 2020, it is estimated that the capacity of the reservoirs increased by $27.7 \%$, rising from 18 to 23 dams in the whole country (XM S.A. E.S.P. 2021b). As a consequence of the energy supply deficit after 2015, the EE presents the fast reduction seen in Figure 5a.

There is an inverse relationship of RV with P (clusters 1 and 3)(Figure 4a), e.i. The decrease in precipitation leads to a water level decline in the dams of the energy matrix, this is evidence of the relationship between the energy system of the country and climate change through climate variables such as $\mathrm{P}$. This is also evidence of the valid clusterization performed based on the PCA method.

Figure 4a shows an inverse relationship between clusters 2 and 4, ED, EP, and Pop are the variables with major influence in this relationship. Cluster 4 vectors show how when ED increases with Pop, this needs a major EP, and this affects negatively the ER. Analysis of T and CE is important since they are variables related to climate change. $\mathrm{T}$ and $\mathrm{CE}$ variables also conform to Cluster 4, with increasing but slightly weaker trends.

The CE trends to increase in developing countries such as Colombia, this due to the link between GHG emissions and activities linked to industry, transport, agriculture, etc. In the case of Colombia $\mathrm{T}$ has the capability to influence the energy structure of the country since the biggest share of the energy mix is dependent on water, a resource-sensitive to $\mathrm{T}$.

An interesting relationship between clusters 1 and 3 is observed, the P has a positive relationship with EE, meaning that when rains are presented a super-habit of energy takes place, and therefore EE increases during these periods. $\mathrm{P}$ is also inversely related to RV, for the same reason when no rains have presented the level of water in the dams decreases leading to fewer reserves. This observation is coherent with the trend in Figure 5. These observations evidence the high vulnerability of the Colombian energy system to climate variations since this energy system is rich in hydropower (70\% hydropower); this is, therefore, evidence of hydropower-RESbased-systems vulnerability to climate change.

\subsection{Variables tendencies}

Figure 5 shows the time series with the selected variables for the vulnerability analysis at the country scale, the plotted data correspond to yearly average values in the time period from 2000 to 2019 in Colombia.

a) 


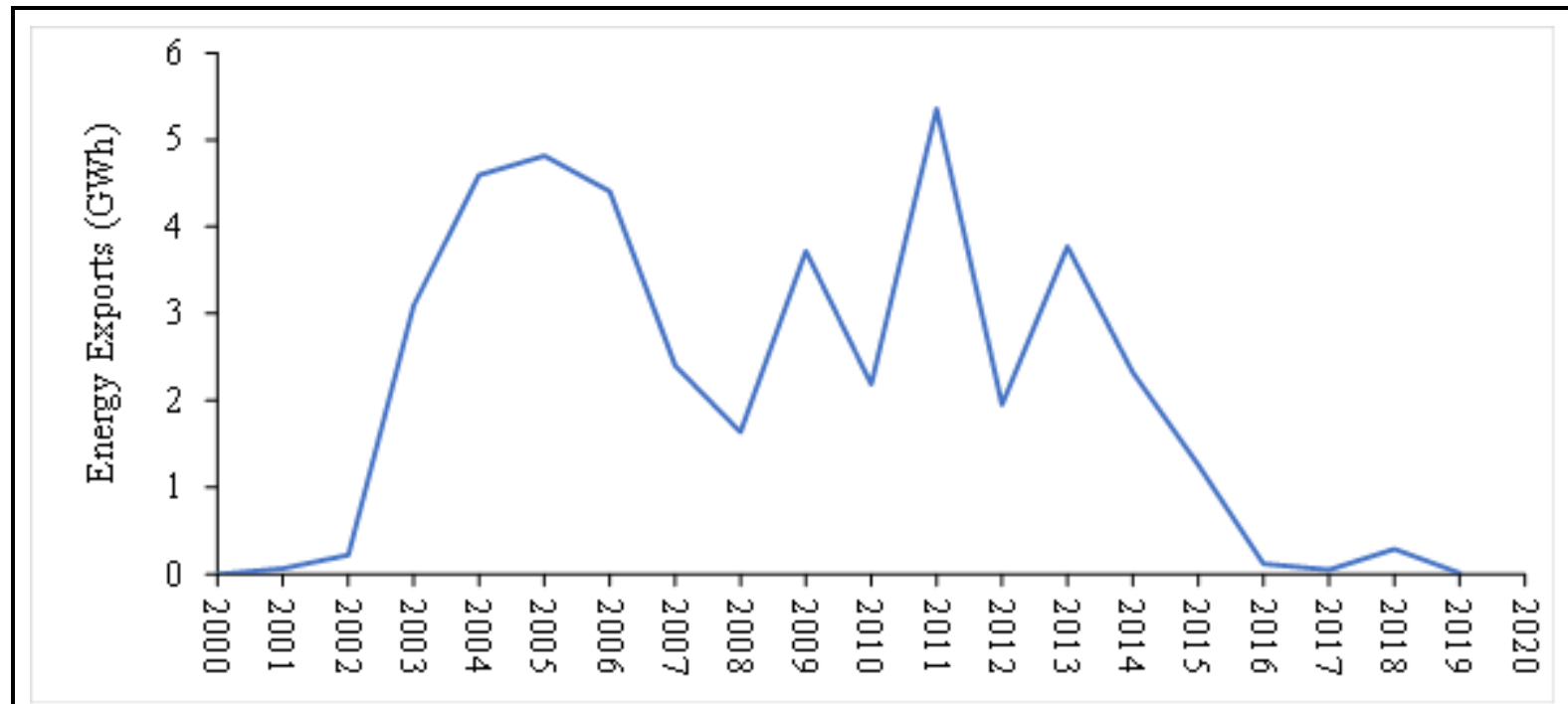

b)

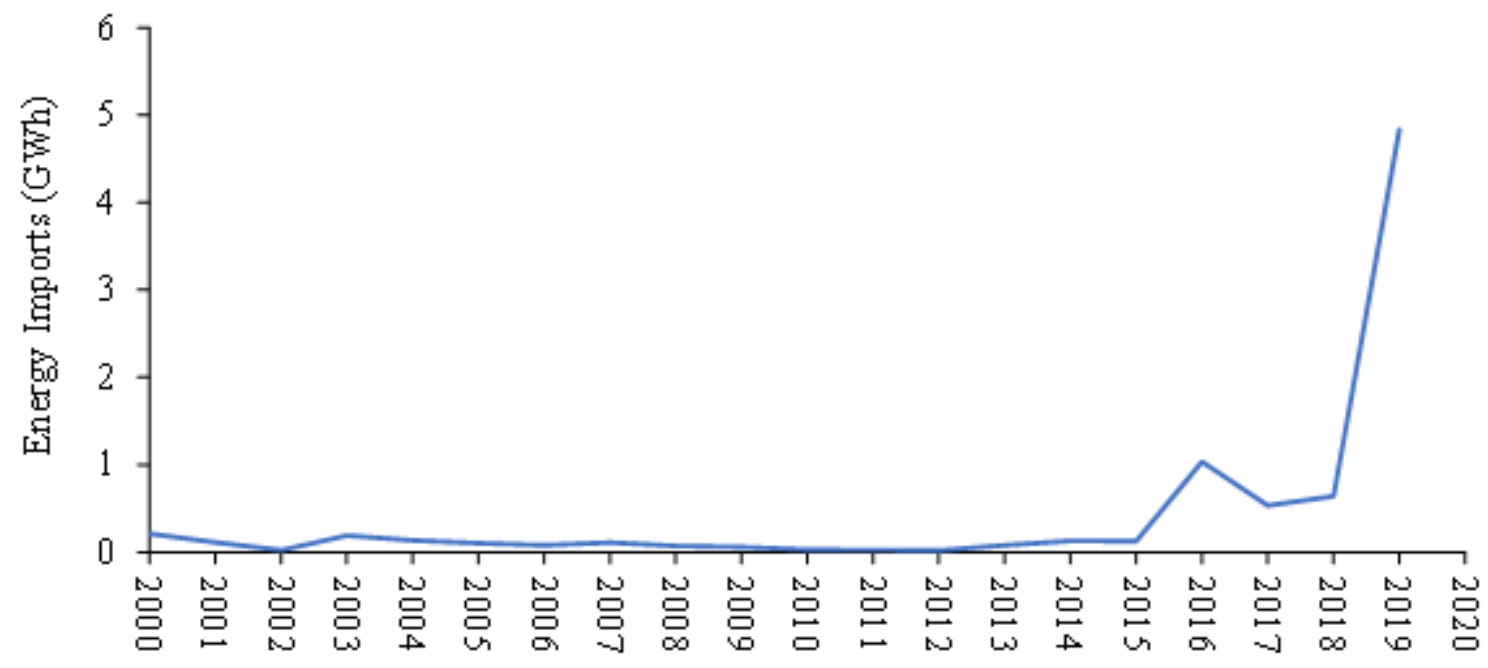

c)

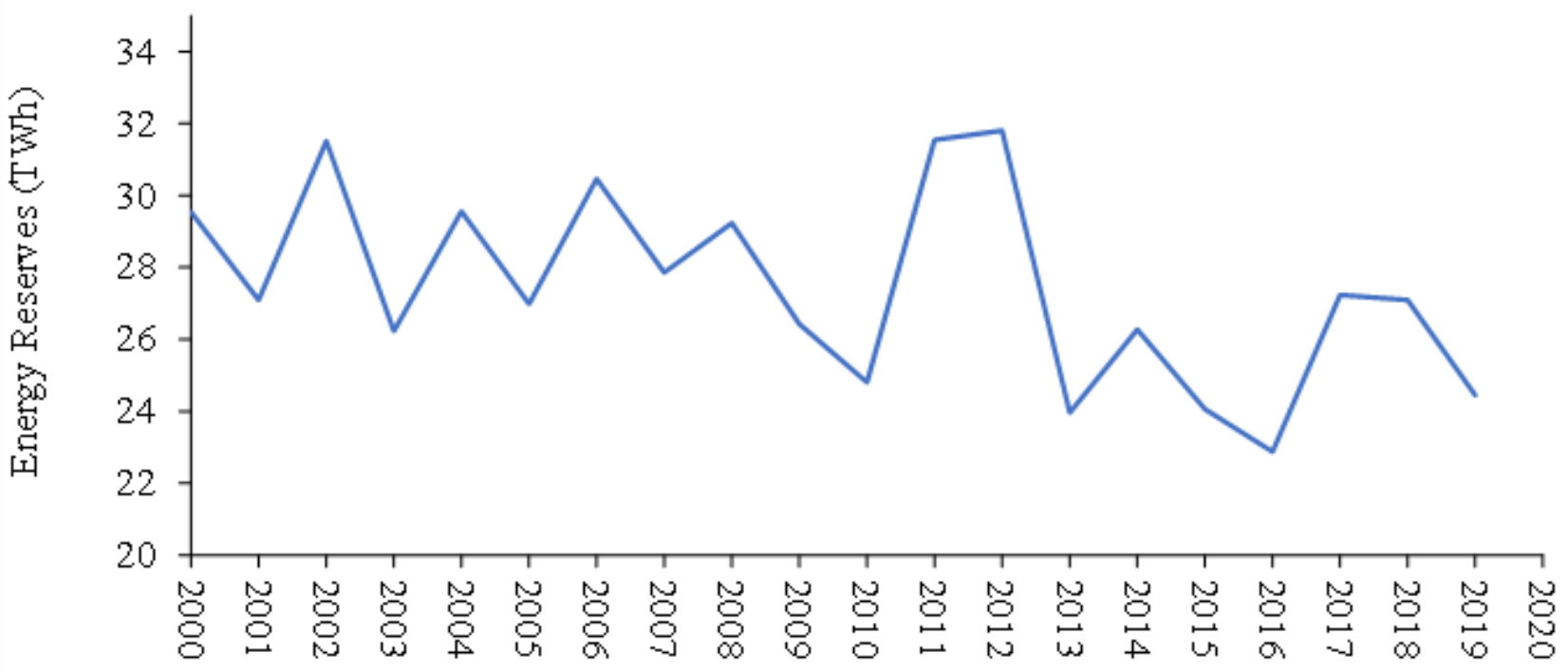




\section{Figure 5. Time series of selected variables for the vulnerability analysis at country scale: a) Energy exports (EE), b) Energy imports (EI), and c) Energy reserves (ER).}

Figure 5a. shows the variation of EE with time during 2000 and 2019. EE was almost $0 \mathrm{GWh}$ in 2000 and progressively increased up to the maximum of $5.5 \mathrm{GWh}$ in 2011, after 2011 the EE has gradually decreased to low values in 2019 .

Figure $5 \mathrm{~b}$ shows the EI which has been relatively small between 2000 and 2015, even so, after 2015 the EI has strongly increased reaching its maximum of $5 \mathrm{GWh}$ in 2019, for 4 years. This EI important increase took place starting in 2015, the same year the start of the last ENSO phenomenon was evidenced, this period of time corresponds also to the EP deficit years shown in Figure 3a.

Figure 5c.shows the ER, this ER has its minimum in 2015-2016 the aforementioned period of time characterized by the last strong ENSO event. differently, the maximum ER is observed in 2010 and 2011, years in which "La Niña" phenomenon took place in South America. Figure 5c shows a net decrease of 4 TWh for ER between 2000 and 2020.

\subsection{Vulnerability evaluation}

\subsubsection{National vulnerability}

To analyze the vulnerability at the national level, the VI was computed using the method proposed in this study. The variables selected based on the PCA and correlation matrix were used for the computation of the VI as suggested in section 2.2.

A VI of 8.64 was estimated for Colombia based on the data from 2000 to 2019. This index value corresponds to $43 \%$ of the maximum possible vulnerability $\left(\mathrm{VI}_{\max }=20\right)$, e.i. The country has $43 \%$ of its maximum possible energy vulnerability to climate change. This percentage represents the vulnerability of SIN regions only in this study.

\subsubsection{Regional vulnerability}

To analyze the distribution of the vulnerability in the country the VI was calculated for all the departments of Colombia. This distribution allows analyzing the vulnerability in spatial terms. Figure 6 shows the percentage of vulnerability in the departments of Colombia, calculated based on the VI proposed in this study for the period between 2000 and 2019. ZNI regions are not included in the map. 


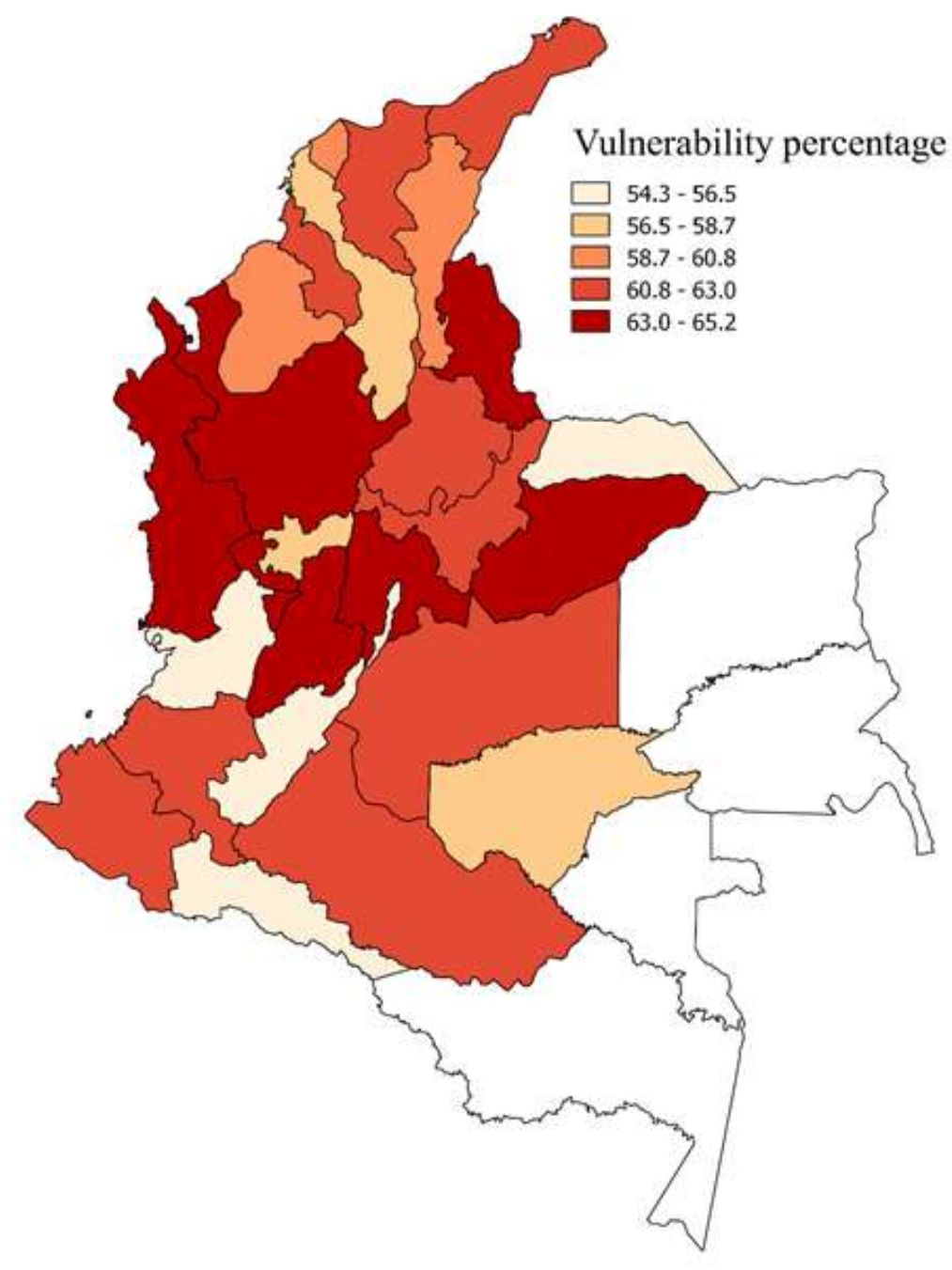

Figure 6. Vulnerability percentage of the maximum possible estimated by department computed from 2011 to 2018

To analyze the spatial distribution of the vulnerability, the average percentage of vulnerability was computed considering the values grouped in 3 ways: 1-north/south, 2-east/west, and 3-per natural region (i.e. Amazonia, Andina, Caribe, Orinoquia, and Pacifica). These 5 natural regions correspond to the national planning regions of the country(Natural Regions of Colombia 2021).

The north/south averages obtained were $61.2 \%$ and $59.5 \%$ for north and south respectively. For the east and west averages, the averages were $60.9 \%$ and $60.5 \%$ respectively. For the averages considering the regions were: Amazonia: 55.5\%, Andina: 61.7\%, Caribe: $60.1 \%$, Orinoquia: $61.0 \%$, and Pacifica: $61.1 \%$. the average for the west. This is due to the distribution of the surface covered by the interconnected areas (SIN) 
since the SIN areas are balanced in east/west, differently to the difference between north and south which is greater, being the north more vulnerable than the south with an average percentage of vulnerability $1.7 \%$ larger.

The region Andina has the largest average percentage of a vulnerability index that might be linked with the large electricity demand in this region. differently, the Amazonia region has the lowest percentage of vulnerability, a result in agreement with the lower electricity demand of this region. Pacific and Orinoquia regions have similar average percentages of vulnerability, with values $0.6 \%$ and $0.7 \%$ lower than the Andina region.

\section{Conclusions}

This study presents a method to evaluate the energy vulnerability to climate change based on a vulnerability index (VI), for this calculation a numerical analysis performed with the PCA method and correlation matrix was performed. The study presents the method to calculate the VI and its implementation using Colombia as a case of study.

Relationships between the variables linked to the energy system and climate change were identified. Evidence linking climate change and energy vulnerability was observed in the relationships of the analyzed variables (Figure 4), e.g. P is inverse to EI, and T inverse to ER. Additionally, the trends of the studied variables with time show the impact of ENSO and "La Niña" phenomena on the system during the period of time between 2000 and 2019 (Figura 3a and Figura 5). This demonstrates that an important risk of energy supply lack in Colombia is linked to hot dry years, and therefore to conditions induced by climate change in the future. This effect also contributes to the estimated vulnerability, e.i. A link between climate change and the increasing energy vulnerability in Colombia was evidenced based on the analysis performed with the variables involved.

The PCA analysis performed on the variables of the Colombian system allowed us to identify relationships between the variables in clusters 1 and 3, leading to identify a high vulnerability of hydropower-RES-basedsystems to climate variation, and therefore to climate change.

The vulnerability of the energy system of Colombia to climate change was quantified as $43 \%$ of its maximum possible at the national SIN scale. The analysis per region was based in the department borderlines of the country SIN areas showing that the higher vulnerability is located in the regions with higher demand (e.g. departments of Andina region), even if they have an important EP infrastructure and are part of SIN. Some regions such as Chocó located at the west of the country on the pacific coast, have a large vulnerability, this can be explained by the lack of EP and transmission infrastructure due to geography and security issues due to the presence of illegal groups.

\section{Acknowledgments}

The authors thank Smart And Simple Engineering S.A.S. (S\&S S.A.S) company for its technical and administrative support to consolidate this research. Thanks to UNAD-ECAPMA and the PIE entitled: "Evaluación y análisis del ruido Ambiental en las Instalaciones de los CEAD (Acacias, Yopal, Cumaral y San José del Guaviare) de la Zona Amazonia Orinoquia ZAO - UNAD" for supporting this study. We acknowledge the research centers NIPEA, and COBIDES, and their members involved in the development of this research.

\section{Ethical Approval}

Not applicable. 
402 Consent to Participate

403 Not applicable.

404 Consent to Publish

405 Not applicable.

406 Authors Contributions

407 LR developed the research and wrote the major part of the manuscript

408 FG Contributed to research internal review and final manuscript versions development

409 MG wrote part of the manuscript, contributed to the vulnerability calculations and research management

410

$411 \quad$ Funding

412 Direct economical founding by the engineering company S\&S S.A.S.

413 Indirect economic founding: UNAD, NIPEA, and COBIDES.

\section{Competing Interests}

415 The authors declare that they have no competing interests.

416 Availability of data and materials

417 Not applicable.

418

419 References

Abdi, H. and Williams, L. J. (2010). Principal component analysis: Principal component analysis. Wiley Interdisciplinary Reviews: Computational Statistics, 2(4), 433-459. https://doi.org/10.1002/wics.101

Bartholomew, D. J. (2010). Analysis and Interpretation of Multivariate Data. In International Encyclopedia of Education (pp. 12-17). Elsevier. https://doi.org/10.1016/B978-0-08-044894-7.01303-8

Berg, R. C., Rechkemmer, A., Espinel, Z., Shultz, J. M. (2020). COVID-19 as a tipping point for Latin America's sustainable development goals: The case of Venezuelan migrants in Colombia. Migration and Development, $0(0), 1-10$. https://doi.org/10.1080/21632324.2020.1830564

Betts, A. (2019). Venezuelan Survival Migration as a Development Opportunity (Forced Migration and International Affairs, Refugee Studies Centre) [Mission Report]. University of Oxford. 
https://www.rsc.ox.ac.uk/files/files-1/research-in-brief-12-venezuelan-survival-migration.pdf

Cuadros, H., Cuellar, Y., Chiriví, J., Guevara-Luna, M. A. (2019). GHG diffuse emissions estimation, and energy security to ENSO using MERRA-2 for largely hydroelectricity-based system. Revista Facultad de Ingeniería Universidad de Antioquia, 91, 70-82. https://doi.org/10.17533/10.17533/udea.redin.n91a07

ECMWF. (2020). ERA-5 Dataset. https://www.ecmwf.int/en/forecasts/datasets/reanalysis-datasets/era5

Fernández-Reyes, R. (2016). El Acuerdo de París y el cambio transformacional. 14.

Gatto, A. (2019). Energy vulnerability around the world:The global energy vulnerability index (GEVI). 36.

Genave, A., Blancard, S., Garabedian, S. (2020). An assessment of energy vulnerability in Small Island Developing States. Ecological Economics, 171, 106595. https://doi.org/10.1016/j.ecolecon.2020.106595

González, M. E. P. (2007). EVOLUCIÓN DE LA TEMPERATURA SUPERFICIAL DESDE EL SIGLO XVIII. 40.

Houghton, R. A. and Woodwell, G. M. (1989). Global Climatic Change. Scientific American, 260(4), 36-47.

International Atomic Energy Agency. (2005). Energy indicators for sustainable development: Guidelines and methodologies. https://www-pub.iaea.org/MTCD/Publications/PDF/Pub1222_web.pdf

Jacobson, M. Z. (2020). 100\% Clean, Renewable Energy and Storage for Everything. Cambridge: Cambridge University Press. 10.1017/9781108786713

Klimenko, V. V., Fedotova, E. V., Tereshin, A. G. (2018). Vulnerability of the Russian power industry to the climate change. Energy, 142, 1010-1022. https://doi.org/10.1016/j.energy.2017.10.069

López, A. R., Krumm, A., Schattenhofer, L., Burandt, T., Montoya, F. C., Oberländer, N., Oei, P.-Y. (2020). Solar PV generation in Colombia-A qualitative and quantitative approach to analyze the potential of solar energy market. Renewable Energy, 148, 1266-1279. https://doi.org/10.1016/j.renene.2019.10.066

Mateus, A. (2016). Crisis energética en Colombia. Tecnología Investigación y Academia, 4(2), 74-81.

Mideksa, T. K. and Kallbekken, S. (2010). The impact of climate change on the electricity market: A review. Energy Policy, 38(7), 3579-3585. https://doi.org/10.1016/j.enpol.2010.02.035

Natural regions of Colombia. (2021). In Wikipedia. 
https://en.wikipedia.org/wiki/Natural_regions_of_Colombia

459 Schaeffer, R., Szklo, A. S., Pereira de Lucena, A. F., Moreira Cesar Borba, B. S., Pupo Nogueira, L. P., 460 Fleming, F. P., Troccoli, A., Harrison, M., Boulahya, M. S. (2012). Energy sector vulnerability to climate change: A review. Energy, 38(1), 1-12. https://doi.org/10.1016/j.energy.2011.11.056

Scholze, N., Riach, N., Glaser, R. (2020). Assessing Climate Change in the Trinational Upper Rhine Region: How Can We Operationalize Vulnerability Using an Indicator-Based, Meso-Scale Approach? Sustainability, 12(16), 6323. https://doi.org/10.3390/su12166323

Seba, T. (2014). Clean Disruption of Energy and Transportation: How Silicon Valley Will Make Oil, Nuclear, Natural Gas, Coal, Electric Utilities and Conventional Cars Obsolete by 2030.

Seba, T. and James, A. (2017). Rethinking Transportation 2020-230: The disruption of transportation and the collapse of the internal-combustion vehicle and oil industries.

The World Bank. (2021, January 12). Data World Bank [Corporate]. World Bank Open Data. https://data.worldbank.org/

UPME. (2020). SIEL - Sistema de Información Eléctrico Colombiano. http://www.siel.gov.co/

UPME. (2021). UPME - Unidad de Planeación Minero Energética. Información y cifras sectoriales. https://www1.upme.gov.co/InformacionCifras/Paginas/Estudios.aspx

Wallace, J. M. and Hobbs, P. V. (2006). Atmospheric Science (2nd ed.). Academic Press.

XM S.A. E.S.P. (2021a, January 12). XM Portal BI Información Inteligente [Corporate]. http://portalbissrs.xm.com.co/Paginas/Home.aspx

XM S.A. E.S.P. (2021b, January 12). XM Portal BI Información Inteligente [Corporate]. http://portalbissrs.xm.com.co/Paginas/Home.aspx 


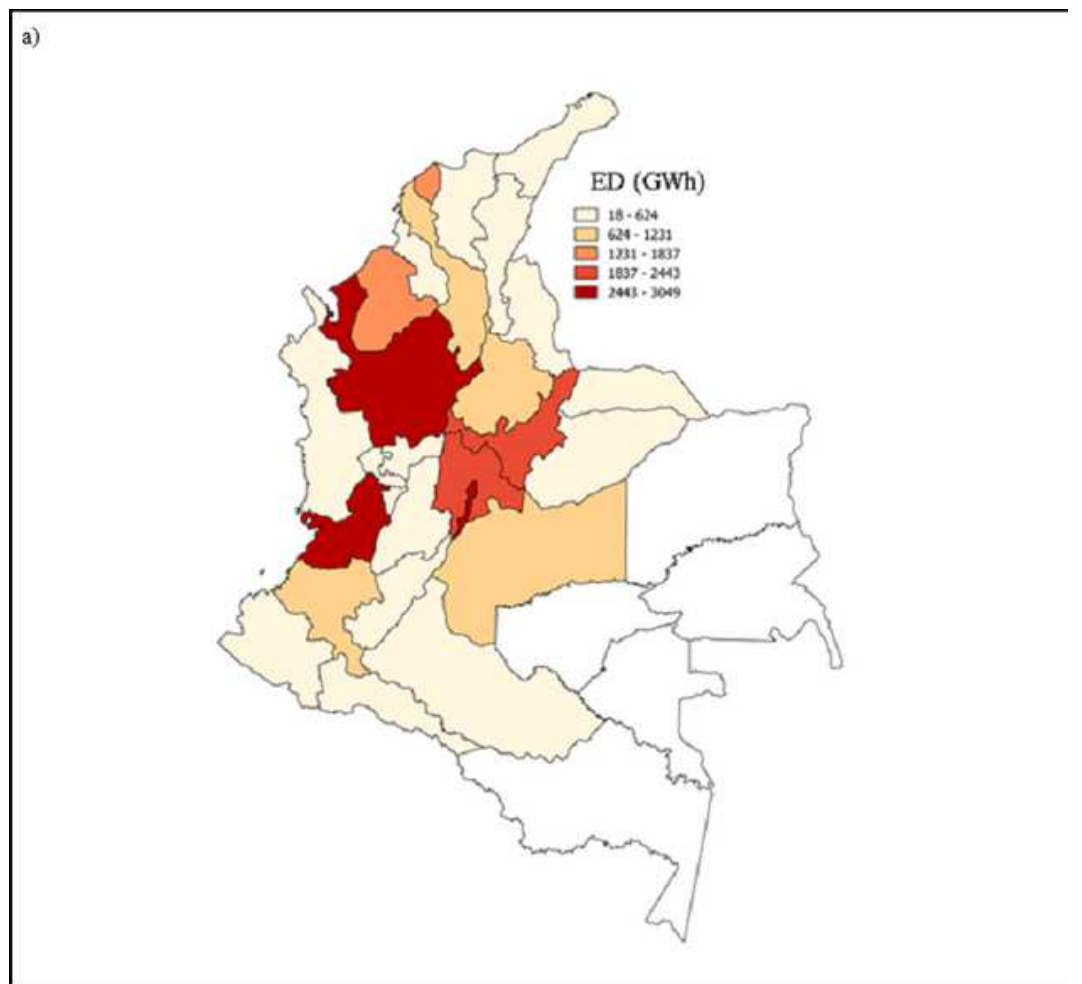

b)

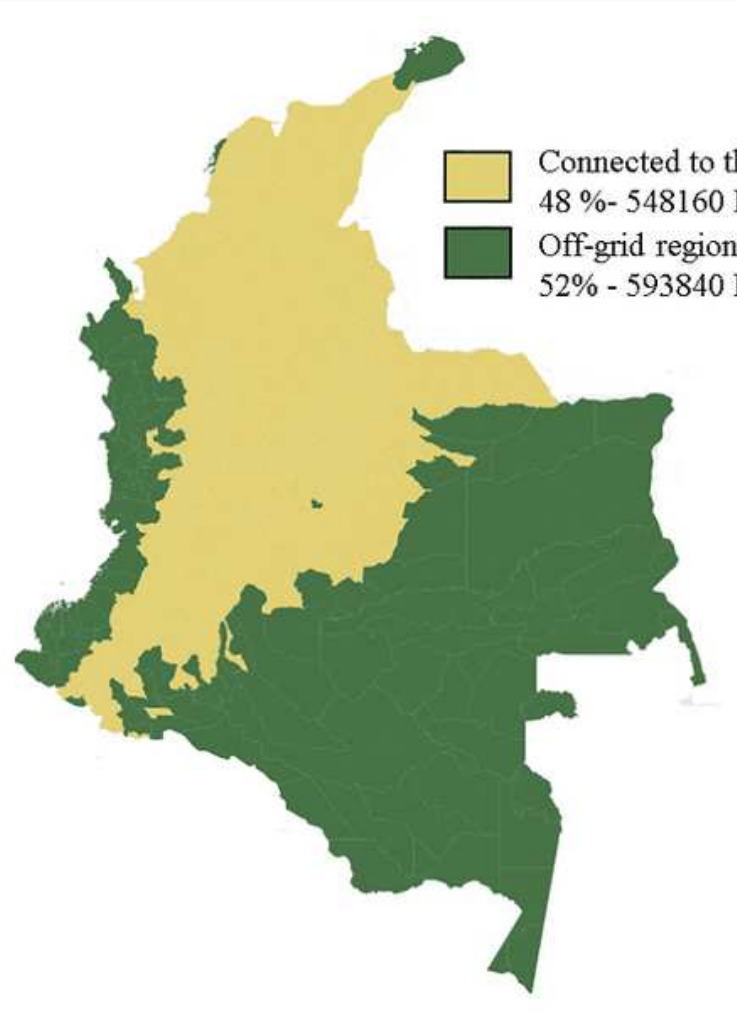

\section{Figure 1}

The current electric energy situation in Colombia: a) Spatial distribution of electric energy demand (ED) in 2019, b) Supply system coverage in terms of areas connected to the grid (SIN) and off-grid regions (ZNI). (Adapted from:(López et al. 2020)) Note: The designations employed and the presentation of the material 
on this map do not imply the expression of any opinion whatsoever on the part of Research Square concerning the legal status of any country, territory, city or area or of its authorities, or concerning the delimitation of its frontiers or boundaries. This map has been provided by the authors.

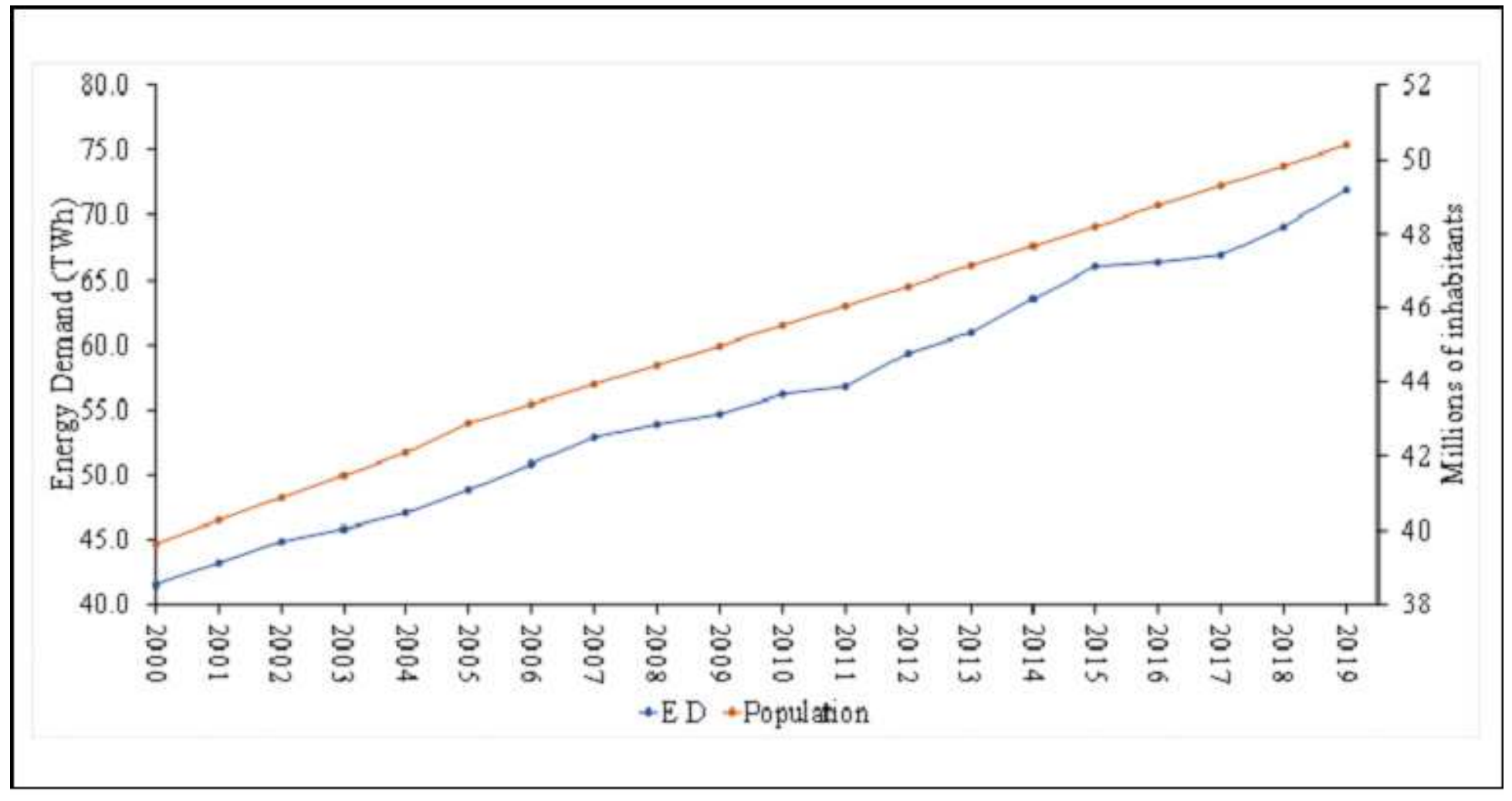

\section{Figure 2}

Population and Energy Demand (ED) in Colombia from 2000 to 2019. 


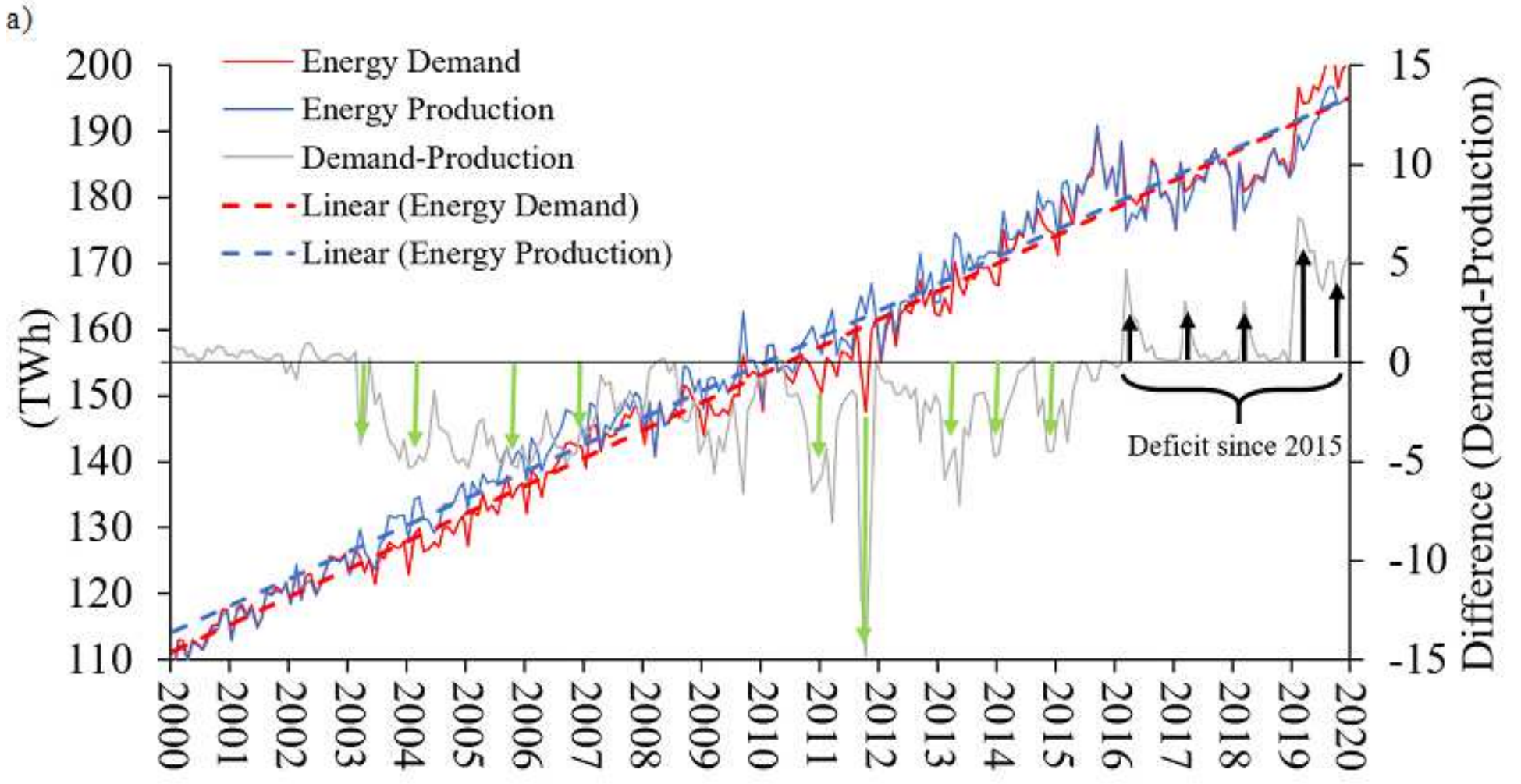

b)

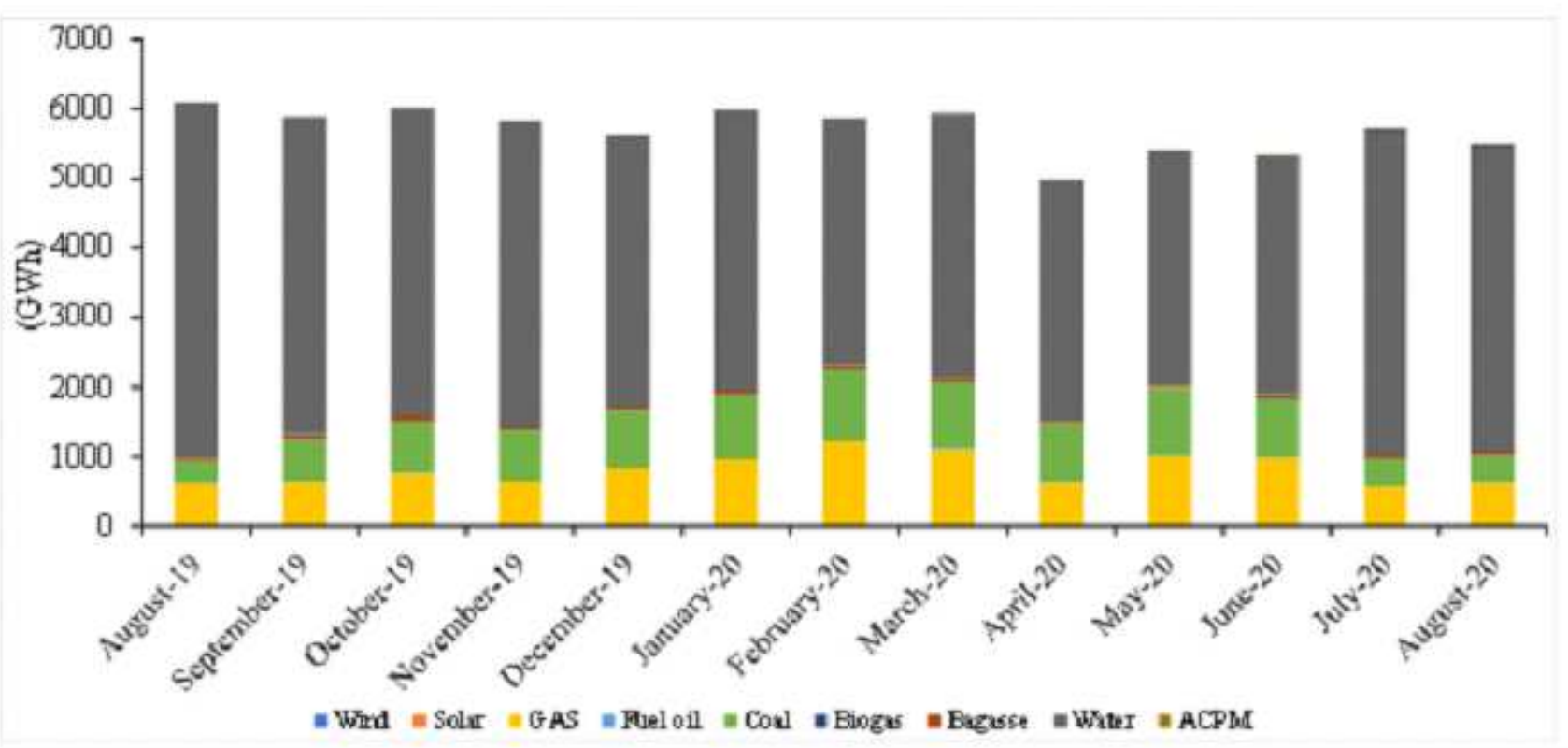

Figure 3

Total energy production and energy demand of Colombia: a) Total electric energy production (EP) and electric energy demand (ED) trend from 2000 to 2020, and b) Energy production by the source from august 2019 to august 2020 (UPME 2020). 


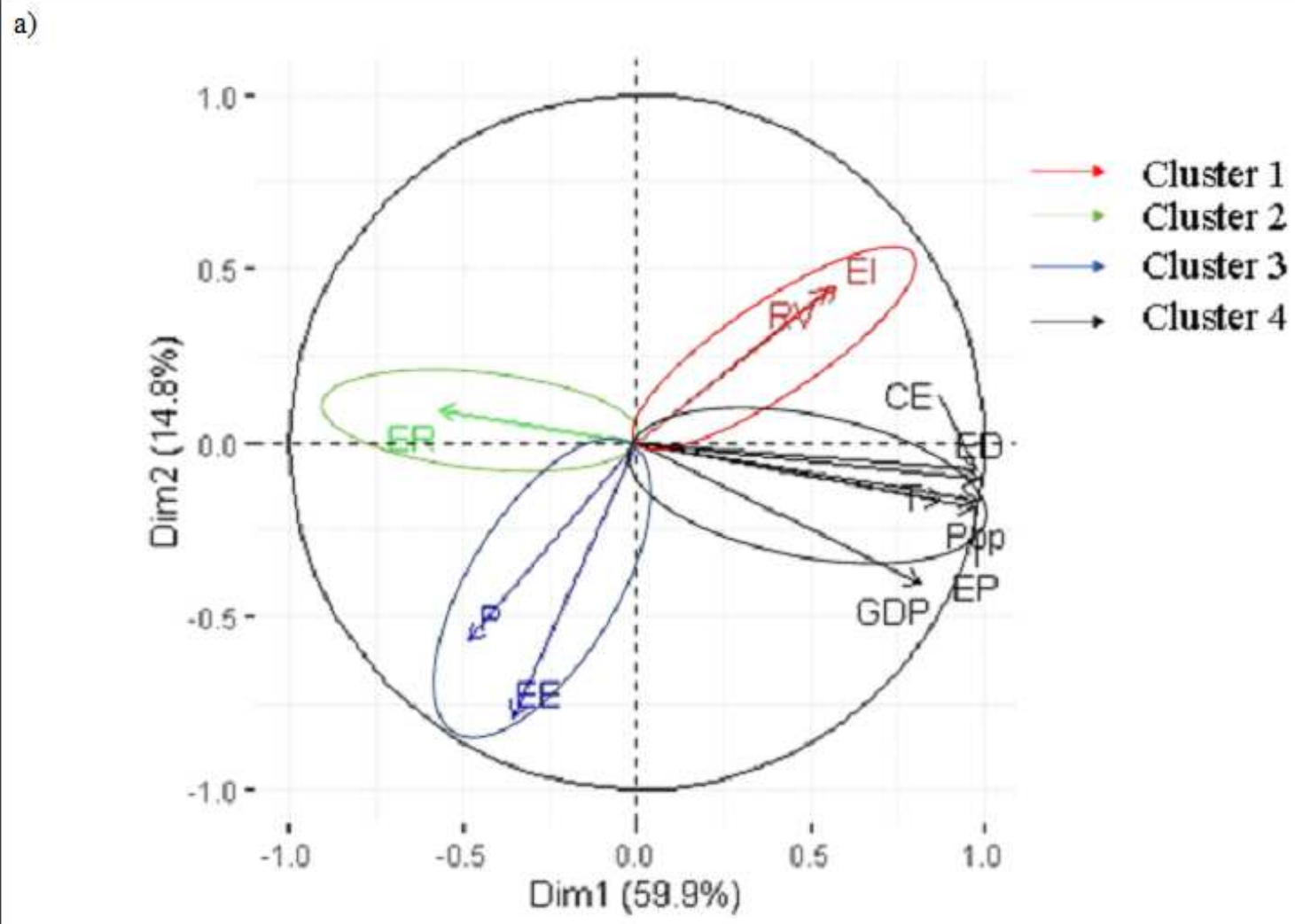

b)

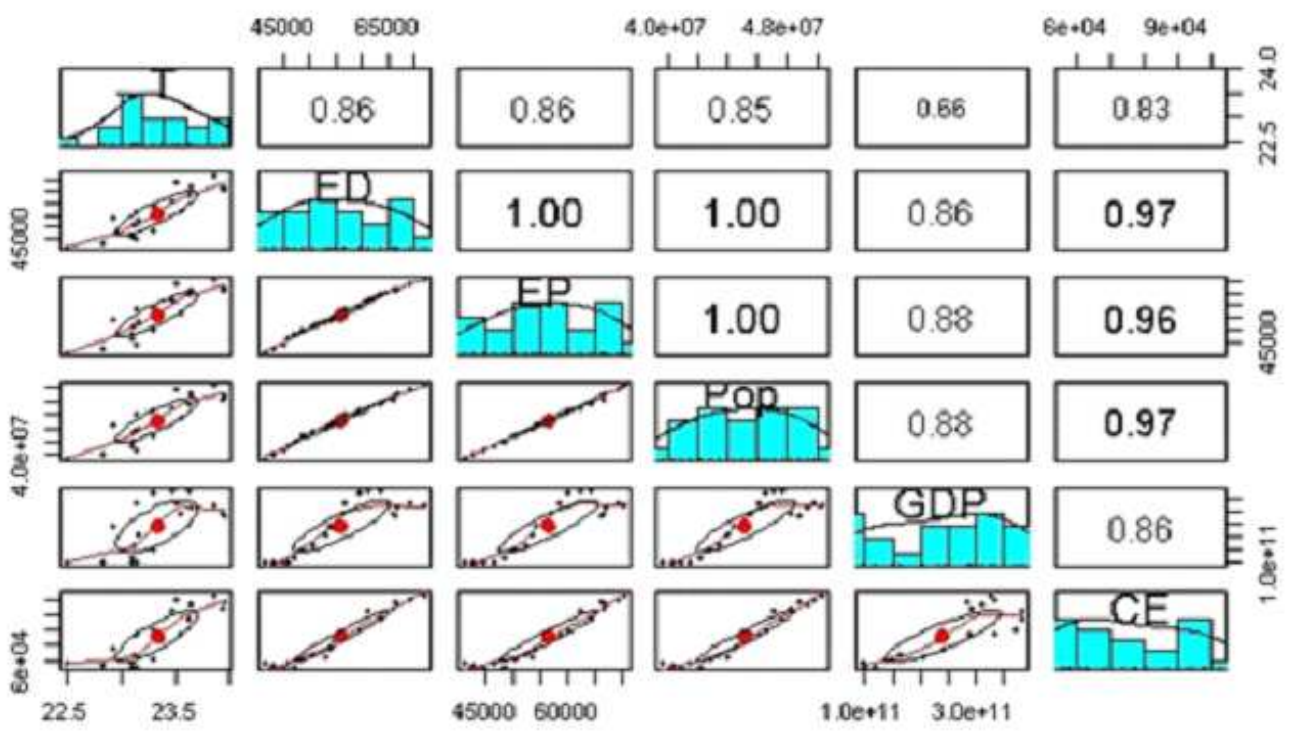

\section{Figure 4}

Selection of variables for calculation of the vulnerability index: (a) PCA (Principal Component Analysis) to identify the representative variables for vulnerability index calculation, (b) Correlation Matrix analysis for Cluster 4. 


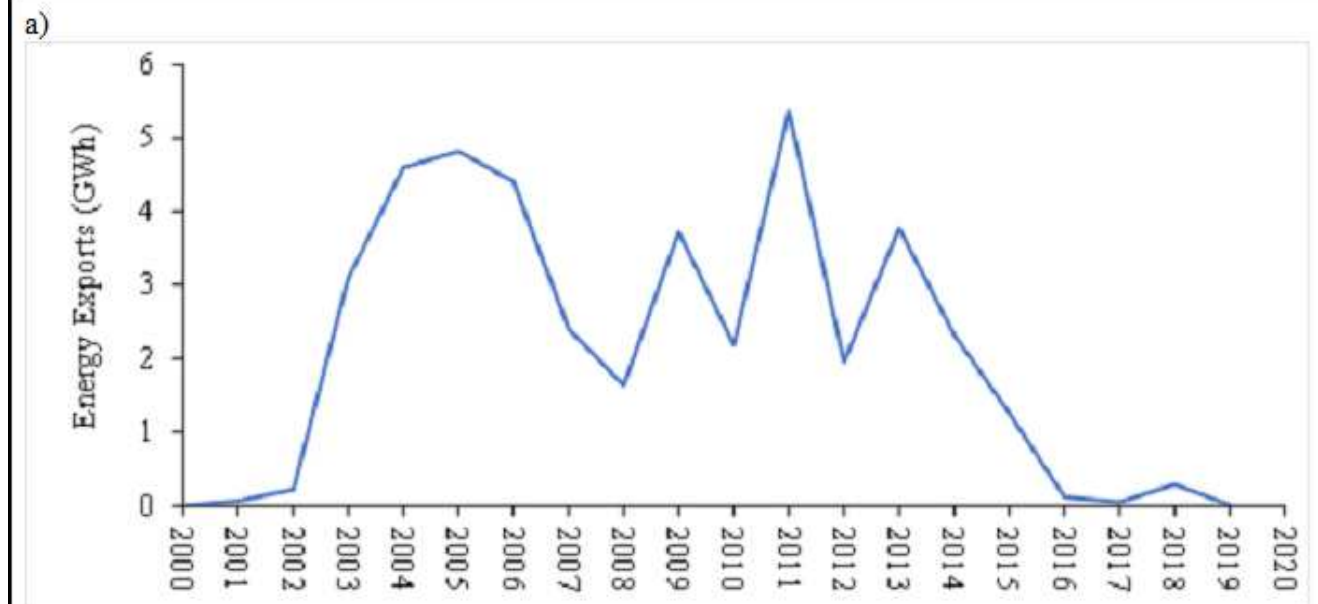

b)

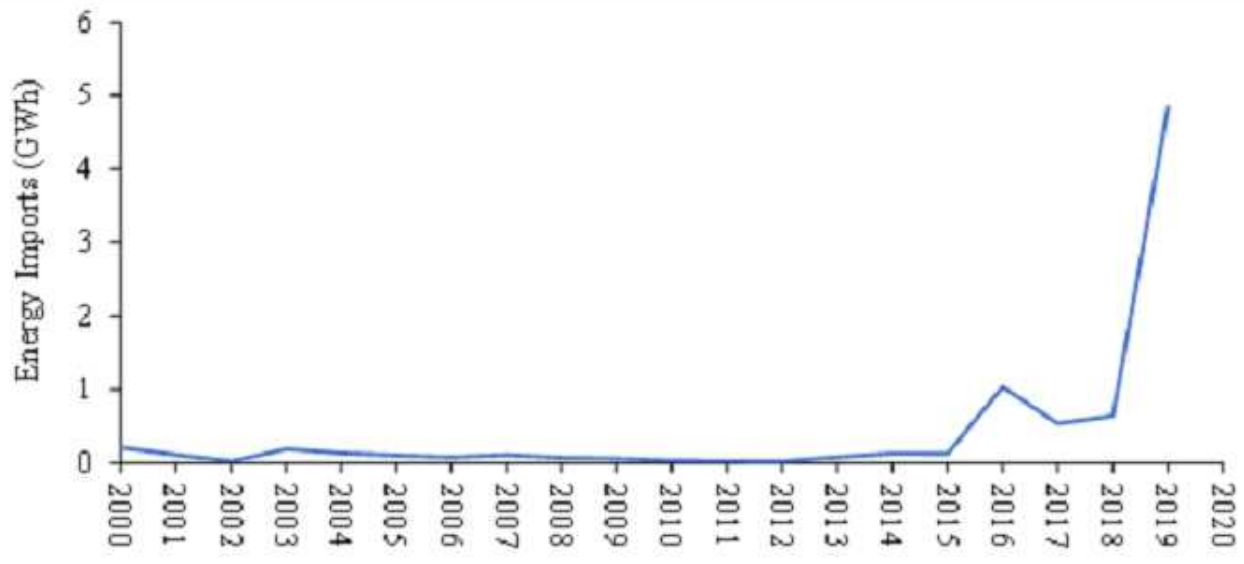

c)

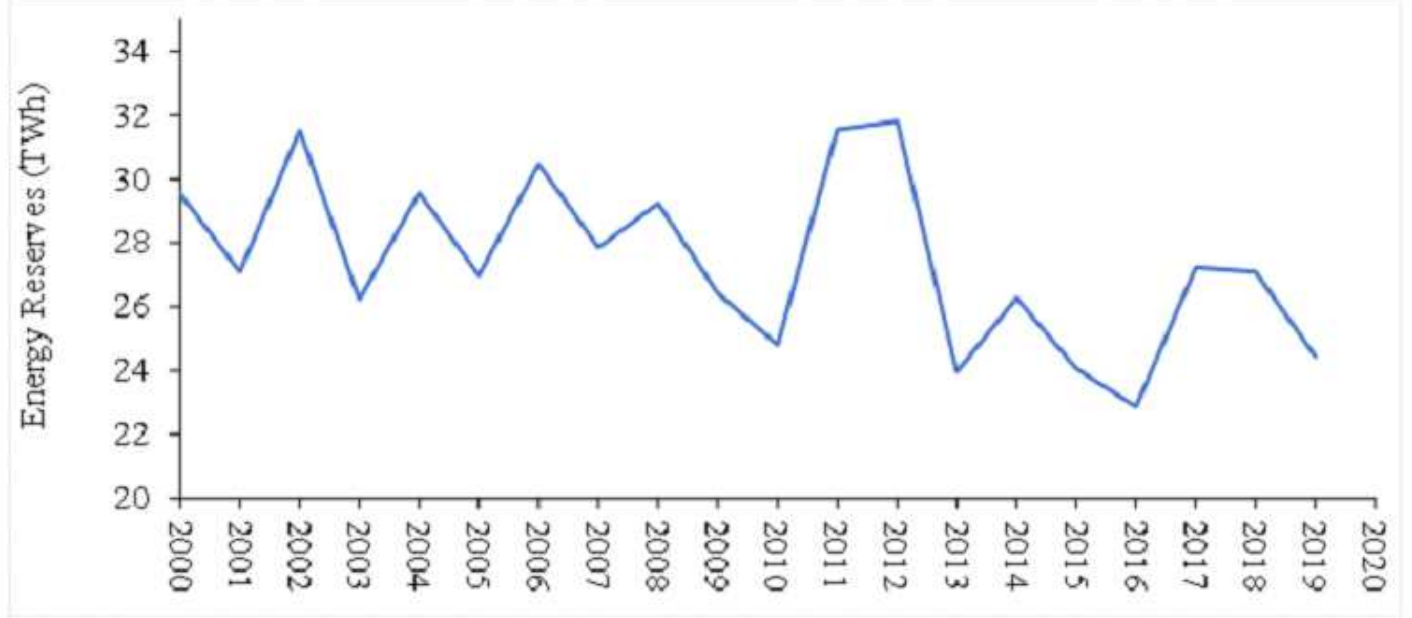

Figure 5

Time series of selected variables for the vulnerability analysis at country scale: a) Energy exports (EE), b) Energy imports (EI), and c) Energy reserves (ER). 


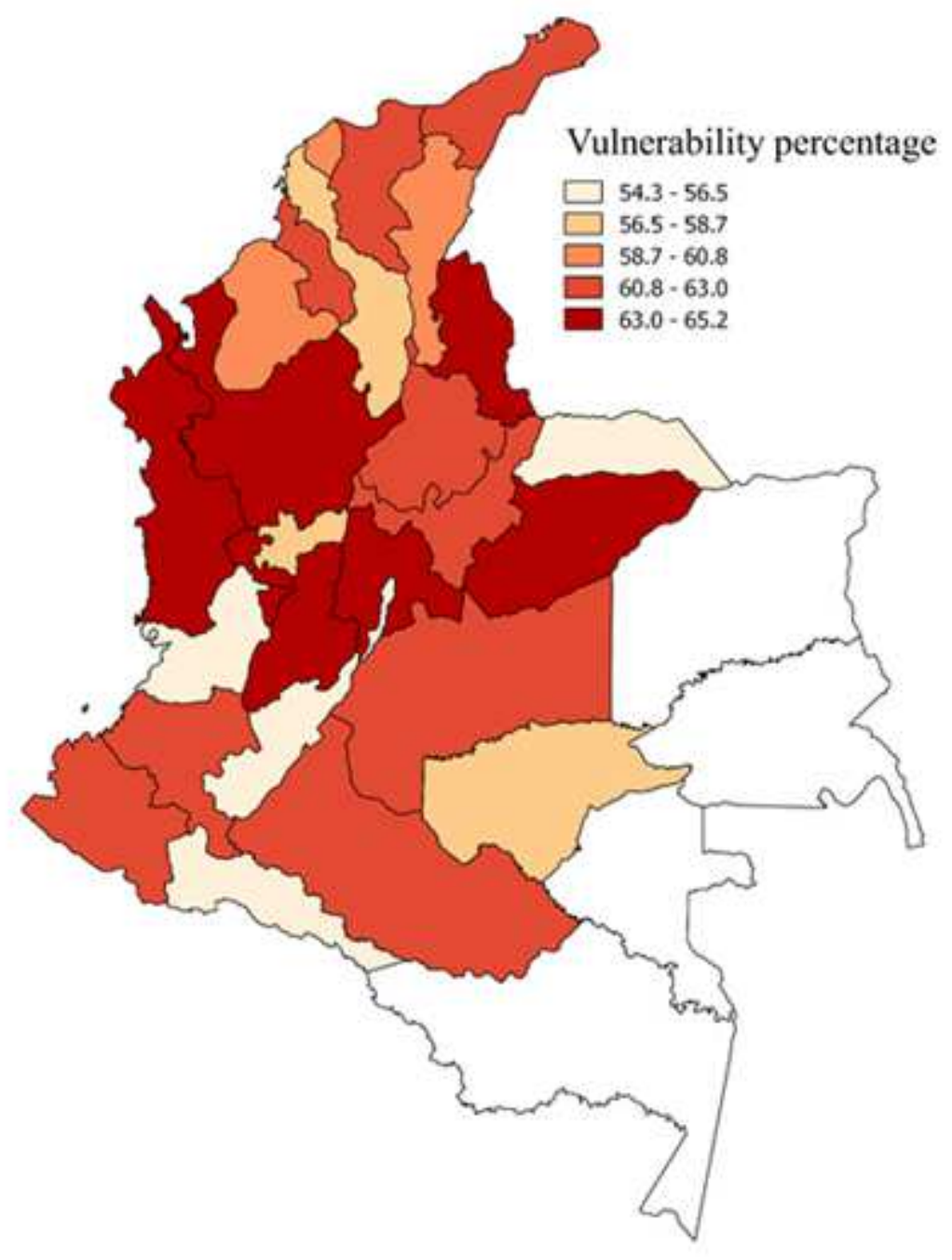

Figure 6

Vulnerability percentage of the maximum possible estimated by department computed from 2011 to 2018 Note: The designations employed and the presentation of the material on this map do not imply the expression of any opinion whatsoever on the part of Research Square concerning the legal status of any country, territory, city or area or of its authorities, or concerning the delimitation of its frontiers or boundaries. This map has been provided by the authors. 